\title{
Marital Rape and its Social Demographic Factors Associated with Gynecological Problems in Kirtipur
}

\author{
Shakya TM${ }^{1}$, Dangal G ${ }^{2}$, Poudyal AK ${ }^{3}$ \\ ${ }^{1}$ Community Based Reproductive Health Care and Counseling Center, Public Health Concern Trust (phect-NEPAL), \\ Kirtipur, ${ }^{2}$ Department of Obstetrics and Gynaecology, Kathmandu Model Hospital, ${ }^{3}$ Department of Community Medicine \\ and Public Health, IOM, Maharajganj, Nepal
}

Received: February 5, 2014; Accepted: August 7, 2014

Aims: This study aimed to find association of marital rape with gynecological problems and socio-demographic factors, which helped to explore possible underlying issues and to provide appropriate services to the women.

Methods: A cross sectional quantitative study was carried out. Three hundred sixty two married women who came to the health care centres of Public Health Concern Trust (phect-NEPAL) for any kind of health services were enrolled for the study. Data was collected through semi structured interview questionnaire. Bivariate analysis and multiple binary logistic regression analysis were applied to identify the factors associated gynecological problems and marital rape.

Results: The study revealed that out of 362 women, 194 (53.6\%) experienced marital rape either everyday or sometime. Out of 362 women, 48.6\% (194) were suffered from gynecological problems. Women who had undergone rape had 2.32 times more likely to experience gynecological problems than those who did not (OR 2.3, 95\% CI 1.52-3.55). Marital rape was found statistical significantly associated ( $\mathrm{p}$-value $<0.05$ ) with economic condition, interspousal communication, and difference among interspousal sexual desire, husband's violent nature, husband's dominant attitude, husband's alcohol intake and gynecological problem.

Conclusions: Marital rape was associated with existence of gynecological problem in the wife. Therefore, women with gynecological problems should also be explored for marital rape and counseling and service should be provided.

Keywords: gynecological problems; health issues; marital rape.

\section{INTRODUCTION}

Sexual violence within marriage is generally considered a private issue, making it difficult for victims to seek and receive support. ${ }^{1}$ It is not paid much attention in Nepal as women are considered as the husband's possessions/insistence for sex. A study done in pregnant women of Maternity Hospital showed among the cases of sexual violence, $45 \%$ of women were victim of marital rape. ${ }^{2}$ A study conducted by Center for Research on Environment Health and Population Activities (CREHPA) has shown that many women reported to have sex against their consent during illness and different exhaustions, menstruation, post partum period and pregnancy

\section{CORRESPONDENCE}

Dr Tara Maiya Shakya

Community Based Reproductive Health Care and Counseling Center, Public Health Concern Trust - Nepal (phect-NEPAL), Kirtipur, Nepal.

Email: tmsall2008@gmail.com

Phone: +977-1-4332548 leading to gynecological problems. ${ }^{3}$ An Indian study by Sudha et $\mathrm{al}^{4}$ suggests marital violence may have a negative impact on multiple aspects of women's reproductive health, including increased self-report of STI symptoms. Women who experienced intimate partner abuse were three times more likely to have a gynecological problem as compared to non-abused women. ${ }^{5,6}$

However, there is dearth of information and limited research elsewhere has shown that sexual violence within marriage (SVM) has profound emotional, psycho-sociological and health consequences. Nonetheless, intervention on marital rape is still been neglected area in Nepal and very few interventions on Gender Based Violence (GBV) are being done in Nepal. This study intended to find association among marital rape and gynecological problems with sociodemographic factors, which would help to explore possible underlying issues and to provide appropriate services to the women. 


\section{METHODS}

A cross sectional study was carried out in the clinics (Kirtipur Hospital, Community Based Reproductive Health Care and Counseling Centre and six outreach clinics) run by Public Health Concern Trust (phectNEPAL) in Kirtipur. The participants were married women who came for any kind of health services within five weeks' period (from August 17, 2009 to September 24, 2009). Three hundred sixty two women were interviewed for the study. A semi structured interview questionnaire was prepared by compilation from the two sources rapid assessment with community women to derive appropriate questions which were then free listed and contextualizing by modification of the gender based violence (GBV) screening tool developed by phect-NEPAL which was prepared in reference with the WHO Quality of life $\mathrm{BREF}^{7}$ and violence against women instrument ${ }^{8}$ and was adopted in the National Reproductive Health Clinical Protocol for Medical Officers developed/ reviewed by Family Health Division, Department of Health Services (DoHS) 2007.9 Women were asked about their demographic characteristics and their spouses, interspousal communication, whether they had arguments, response on unresolved issues, husband's male dominant characters, use of alcohol, marital rape related information like difference in sexual desire, ability to refuse sex, reaction of husband when refused for sex, initiation of marital rape and status of gynecological problems (white discharge, prolapse uterus, pain lower abdomen, amenorrhoea, dysfunctional uterine bleeding). Qualitative and quantitative data were collected. Ethical approval was taken from Institutional Review Board, Institution of Medicine (IOM) and from phect-NEPAL for the study. Verbal consent was taken from each respondent. The interview was taken in a private room in the health centre. Confidentiality and privacy were maintained and the respondents were made assured of it. The participants were referred to the appropriate operators (gynaecologist, medical doctor, psychologist, legal counselor or referral centres (Kathmandu Model Hospital, Forum for Women Law and Development, Legal Aid and Consultancy Centre) for information and services if they require any assistance.

The researcher carried out data compiling, checking, editing and coding. The data was entered in Epi Info 3.5 and analysis was done using SPSS 13.0.
Descriptive analysis was performed as per the study variables at the initial stage. Bivariate analysis of marital rape and associated factors was conducted. All variables significant at 0.05 level of significance in bivariate analysis were considered for multivariate logistic analysis. The goodness of fit of the logistic model was done with Hosmer-Lemeshow Chi-sqare test.

\section{RESULTS}

The majority of the respondents were between 25 to 49 years age, which comprised $72.4 \%$ of total respondents $(n=362)$. The mean and standard deviation of age were 34.9 and 10.66 years respectively.

\begin{tabular}{|c|c|c|}
\hline Characteristics & Number & $(\%)$ \\
\hline \multicolumn{3}{|l|}{ Age } \\
\hline Below 25 & 59 & $(16.3)$ \\
\hline $25-49$ & 262 & $(72.4)$ \\
\hline 50 and above & 41 & $(11.3)$ \\
\hline \multicolumn{3}{|l|}{ Caste/ethnicity } \\
\hline Janajati & 264 & $(72.9)$ \\
\hline Brahmin and Chhetri & 88 & $(24.3)$ \\
\hline Others & 10 & $(2.8)$ \\
\hline \multicolumn{3}{|l|}{ Education } \\
\hline Illiterate & 122 & $(33.7)$ \\
\hline Primary and secondary & 184 & $(50.8)$ \\
\hline Above secondary & 56 & $(15.5)$ \\
\hline \multicolumn{3}{|l|}{ Economic status } \\
\hline $\begin{array}{l}\text { Adequate with some } \\
\text { saving }\end{array}$ & 46 & $(12.7)$ \\
\hline Adequate with no saving & 274 & $(75.7)$ \\
\hline Not sufficient & 42 & $(11.6)$ \\
\hline \multicolumn{3}{|l|}{ Type of family } \\
\hline Single & 216 & $(59.7)$ \\
\hline Joint & 133 & $(36.7)$ \\
\hline Extended & 13 & $(3.6)$ \\
\hline \multicolumn{3}{|l|}{ Age at marriage } \\
\hline Below 20 & 166 & $(45.9)$ \\
\hline $20-24$ & 151 & $(41.7)$ \\
\hline 25 and above & 45 & (12.4) \\
\hline \multicolumn{3}{|l|}{ Types of marriages } \\
\hline Arranged & 225 & $(62.2)$ \\
\hline $\begin{array}{l}\text { Love marriage, court } \\
\text { marriage and others }\end{array}$ & 137 & $(37.8)$ \\
\hline
\end{tabular}


A very few 65 (18\%) women had daily interspousal communication. In argument, around 16\% (47) women reported that their spouses physically forced them.

\begin{tabular}{|c|c|c|}
\hline Characteristics & Numb & $\mathbf{r} \quad(\%)$ \\
\hline \multicolumn{3}{|l|}{$\begin{array}{l}\text { Interspousal } \\
\text { communication }\end{array}$} \\
\hline Daily & 65 & $(18.0)$ \\
\hline Sometimes and never & 297 & $(82.0)$ \\
\hline \multicolumn{3}{|l|}{ Interspousal arguments } \\
\hline Yes & 289 & $(79.8)$ \\
\hline \multicolumn{3}{|l|}{$\begin{array}{l}\text { Response on unresolved } \\
\text { issues }(n=289)\end{array}$} \\
\hline Do not talk/ignore & 134 & $(46.4)$ \\
\hline Simple scolding & 108 & $(37.4)$ \\
\hline Severe scolding & 76 & $(26.3)$ \\
\hline $\begin{array}{l}\text { Application of physical } \\
\text { force }\end{array}$ & 47 & $(16.3)$ \\
\hline Throwing objects & 14 & $(4.8)$ \\
\hline Tried to smother & 6 & $(2.1)$ \\
\hline Other & 11 & $(3.8)$ \\
\hline \multicolumn{3}{|l|}{ Male dominant character } \\
\hline Yes & 146 & $(40.3)$ \\
\hline No & 216 & $(59.7)$ \\
\hline \multicolumn{3}{|l|}{ Use of alcohol by husband } \\
\hline Yes & 227 & $(62.7)$ \\
\hline No & 135 & $(37.3)$ \\
\hline
\end{tabular}

The respondents were asked on marital rape related information like interspousal differences in sexual desire, wife's ability to refuse sex, husband's reaction towards her refusal, initiation of the marital rape, occurence of marital rape and gynecological problems among the married women seeking care. Table 3 shows that 194 (53.6\%) women experienced marital rape either everyday or sometime. Out of 362 women, $48.6 \%$ (176) were suffered from gynecological problems.

The study revealed that women who had undergone rape had 2.32 times more likely to experience gynecological problems than those who did not (OR 2.3 , 95\% CI 1.52 -3.55). Among the gynecological problems, the strongest statistical association was between marital rape and women's complaint of white and smelly discharge (OR 18.8, 95\% CI 10.54$53.79)$ in compare to the respondents having other medical problems (OR 0.98, 95\% CI 0.53-1.81).

\begin{tabular}{|lrr|}
\hline \multicolumn{2}{|l|}{ Table 3. Marital rape related information ( $\mathrm{n}=362)$} \\
\hline Characteristics & Number & $\mathbf{( \% )}$ \\
Difference in sexual desire & & \\
$\quad$ Yes & 314 & $(86.7)$ \\
No & 48 & $(13.3)$ \\
Ability to refuse sex & & \\
Yes & 255 & $(81.2)$ \\
No & 59 & $(18.8)$
\end{tabular}

$\begin{array}{lll}\begin{array}{l}\text { Reaction of husband when } \\ \text { refused for sex (multiple } \\ \text { responses) }\end{array} & & \\ \begin{array}{l}\text { Angry/abuse with bad } \\ \text { words }\end{array} & 147 & (40.6) \\ \begin{array}{l}\text { Compromise when said } \\ \text { with cause }\end{array} & 88 & (24.3) \\ \text { Ignore } & 62 & (17.1) \\ \text { Beating } & 42 & (11.6) \\ \text { Goes to other women } & 19 & (5.2) \\ \text { Comes home late or does } & 12 & (3.3) \\ \text { not come home } & 14 & (3.9) \\ \text { Others } & & \end{array}$

Occurence of marital rape

in the married women

seeking care

Marital rape

$194 \quad(53.6)$

\section{Initiation of marital rape} $(n=194)$

$\begin{array}{lrl}\text { From the day of wedding } & 73 & (37.6) \\ \text { During menstruation } & 8 & (4.1) \\ \text { During pregnancy } & 10 & (5.2) \\ \text { During post natal period } & 10 & (5.2) \\ \text { During illness } & 22 & (11.3) \\ \text { Do not remember } & 69 & (35.6) \\ \text { Others } & 2 & (1.0)\end{array}$

\section{Gynaecological problem}

Yes

$176 \quad(48.6)$

No

The association between marital rape and possible individual and socio-demographic variable was assessed at 95\% CI in the multivariate analysis. The factors that were significant ( $p$-value $<0.05$ ) were economic condition, interspousal communication, and difference among interspousal sexual desire, husband's violent nature, husband's dominant attitude, husband's alcohol intake and gynecological problem. 


\begin{tabular}{|c|c|c|c|c|c|c|}
\hline \multirow{3}{*}{ Characteristics } & \multicolumn{4}{|c|}{ Marital rape } & \multirow{3}{*}{ OR } & \multirow{3}{*}{$95 \% \mathrm{CI}$} \\
\hline & \multicolumn{2}{|c|}{ Yes $(n=194)$} & \multirow{3}{*}{\multicolumn{2}{|c|}{$\begin{array}{cc}\text { No } & (\mathrm{n}=168) \\
\text { N } & \%\end{array}$}} & & \\
\hline & $\mathbf{N}$ & $\%$ & & & & \\
\hline \multicolumn{5}{|l|}{ Gynaecological problem } & & \\
\hline Yes & 113 & 62.4 & 63 & 35.8 & \multirow{3}{*}{2.32} & \multirow{3}{*}{$1.52-3.55$} \\
\hline No & 81 & 435 & 105 & 565 & & \\
\hline Health Problems & & & & & & \\
\hline White/smelly discharge & 161 & 78.2 & 45 & 21.8 & 18.88 & $10.54-53.79$ \\
\hline Prolapsed uterus & 18 & 66.7 & 9 & 33.3 & 3.43 & $1.21-9.66$ \\
\hline Pain lower abdomen & 59 & 54.1 & 50 & 45.9 & 0.47 & $0.25-0.90$ \\
\hline Amenorrhoea & 36 & 49.3 & 37 & 50.7 & 1.11 & $0.51-2.41$ \\
\hline $\begin{array}{l}\text { Dysfunctional uterine bleeding } \\
\text { (DUB) }\end{array}$ & 18 & 60.0 & 12 & 40.0 & 1.58 & $0.58-4.32$ \\
\hline Other/medical problem & 103 & 53.6 & 89 & 46.4 & 0.98 & $0.53-1.81$ \\
\hline
\end{tabular}

\begin{tabular}{|c|c|c|c|c|}
\hline Variables & Unadjusted OR & 95\% CI & Adjusted OR & 95\% CI \\
\hline $\begin{array}{l}\text { Gynaecological problem } \\
\text { (Yes/No) }\end{array}$ & 2.32 & $1.52-3.55$ & 2.26 & $1.29-3.94$ \\
\hline \multicolumn{5}{|l|}{ Economic condition } \\
\hline \multicolumn{5}{|l|}{ Adequate with some saving } \\
\hline Adequate with no saving & 2.23 & $1.16-4.28$ & 1.22 & $0.54-2.76$ \\
\hline Inadequate & 4.18 & $1.71-10.20$ & 1.05 & $0.35-3.19$ \\
\hline \multicolumn{5}{|l|}{ Interspousal communication } \\
\hline Daily & - & - & - & - \\
\hline Never and sometimes & 1.80 & $1.04-3.11$ & 1.67 & $0.81-3.40$ \\
\hline $\begin{array}{l}\text { Difference among interspousal } \\
\text { sexual desire (Yes/No) }\end{array}$ & 2.91 & $1.52-5.58$ & 4.42 & $1.93-10.14$ \\
\hline Male dominant attitude (Yes/No) & 4.29 & $2.71-6.80$ & 2.54 & $1.44-4.47$ \\
\hline \multicolumn{5}{|l|}{ Husband's violent nature } \\
\hline Severe scolding & 3.70 & $1.50-9.09$ & 4.55 & $2.07-9.96$ \\
\hline Husband takes alcohol (Yes/No) & 2.29 & $1.48-3.54$ & 1.85 & $1.05-3.25$ \\
\hline
\end{tabular}

\section{DISCUSSION}

This study was conducted to find association among marital rape and gynecological problems with sociodemographic factors of married women in Kirtipur, Nepal. In this study the wives gave all the views and husband's perspectives were not explored. The time limit for the experiencing of marital rape was not considered and the study site was only limited to the six outreach clinics, community based clinic and Kirtipur Hospital of phect-NEPAL, Kirtipur. This study revealed that the prevalence of marital rape was $53.6 \%$, which was higher than the national and international average. The studies from different countries showed different data from country to country, in community to community. In WHO multi country study, the range of lifetime prevalence of sexual violence by an intimate partner was between 6\% (Japan city and Serbia and Montenegro city) and $59 \%$ (Ethiopia province), with most sites falling between $10 \%$ and $50 \%{ }^{10}$. Marital rape is common contributing to almost $45 \%$ of sexual violence. It is not uncommon during menstruation, pregnancy or 
immediate postpartum. More than half (51.8\%) of the respondents had been forced to have sex when ill; 46 percent were coerced immediately after discharge from the hospital (most often after childbirth). ${ }^{2}$ For most women in Nepal, first sexual intercourse occurs at the time of first marriage comprising of $29 \% \cdot{ }^{11}$ In a study in Nepal done by Institute for Social and Gender Equality (SAMANATA), $42 \%$ of the respondents had indicated forced sexual intercourse during last or earlier pregnancy while $24 \%$ had indicated that it happened sometimes or during non-pregnant times. ${ }^{12}$

In this study, the age of the women was not found to be significant in relation to the occurrence of marital rape. However in logistic regression, in structural equation modeling (SEM) the reciprocal value is significant for the age 50 and above (in the menopause state) than in the age 24 and below. In a study conducted in married women aged 15-24, approximately $74 \%$ of the young women mentioned 'sex against one's wishes' as sexual violence within marriage (SVWM). Sixty-two percent of respondents described 'forced sex during illness' and 'forced sex after consumption of alcohol' as SVWM. ${ }^{13}$

NDHS 2011 showed that $38 \%$ of ever-married women age 15-49 experienced sexual violence from their illiterate husband and $13 \%$ from husband with higher education. ${ }^{11}$ This study revealed that there are no differences in the husbands' education for happening marital rape. However, in logistic regression, in structural equation modeling (SEM) the reciprocal value is significant for the husbands' illiteracy $(56 \%)$. Regarding the factors affecting marital rape, no one factor alone "causes" violence but rather a combination of factors that raises the likelihood that a particular man in a particular setting will react violently. The social and cultural normsthat assert men's superiority over women- combined with individual level factors- such as alcohol determine the likelihood of marital rape. Because of the heterogeneity in sexual aggression, there is unlikely to be a single alcohol-sexual aggression relationship. Rather, there appear to be different ways in which chronic and acute alcohol consumption may influence sexual aggression, depending upon situational and individual characteristics. ${ }^{14}$ Women whose husbands get drunk often are more than three times as likely to experience sexual violence as women whose husbands do not drink. ${ }^{11}$ No or little inter-spousal communication and low autonomy of women significantly increases the odds of experiencing violence among married women. ${ }^{15}$ This study showed that gynecological problem along with husband's male dominant attitude, inter-spousal communication and alcohol intake by husband were seen a strong association with marital rape.

This study showed that compared to those couple who shared their daily experience each other, the couple who seldom shared their daily experience were 1.8 times more likely to experienced marital rape.

The women with the different feeling of their sexual desire than their husbands, experienced marital rape by almost three times higher than those who did not think the difference in their sexual desire. But when it was adjusted with other variables like gynecological problem of wife, male dominant nature of husband, alcohol intake by husband, and inter-spousal communication, the occurrence of marital rape showed 4.4 times higher. In the other words, not a single factor can cause violence but rather need to think of combination of other factors too. A study on "gynecological impact of sexual and physical abuse by spouse" revealed that among all the women with gynecological symptoms, $17 \%$ have had sexual problems and reported abuse by spouse was associated with a higher frequency of gynecological symptoms at the time of interview. ${ }^{16}$ And another study conducted in military women, the number of vaginal assaults women experienced was significantly and positively associated with frequency of pelvic pain, vaginal bleeding/discharge, painful intercourse, and painful urination. ${ }^{17}$ In this study, among the health complaints made, the respondents during the clinic visit, white/smelly discharge showed the strongest association with the marital rape. The existence of marital rape was 18 times higher among those women who came to the clinic with white and smelly discharge, followed by 3 times higher in those who came with the complaint of something coming out of vagina (uterine prolapse) for which reference was not having those complaints. The consequences of marital rape for women are numerous and can include post-traumatic stress disorder and depression, vaginal or anal stretching, cystitis, miscarriage, unwanted pregnancies, sexually transmitted infections, sexual dysfunction and chronic genital pain. ${ }^{6} 18$ This study revealed that there was an association between marital 
rape and diagnosed gynecological problem. Sixty four percent of women with gynecological problem had experienced marital rape that is, more than double the chance of having marital rape with women who were diagnosed as gynecological problem (OR 2.32, 95\% CI 1.52 - 3.55). Nonetheless, adjusting with other variables, the occurrence of marital rape for the gynecological problem was not much changed in comparison to unadjustment of other variables. This reveals that gynecological problem is associated with marital rape.

\section{CONCLUSIONS}

The study investigated marital rape, key factor affecting it and gynecological problems of married women of Kirtipur. The study showed the prevalence of marital rape was $53.6 \%$. Among them $24.9 \%$ had experienced marital rape regularly while $28.7 \%$ occasionally. This study showed that there is no direct relationship of age of the woman with the marital rape. This study showed those women who had undergone marital rape experienced gynecological problems by more than two times than those who did not. Therefore, women who visit the health facilities with gynecological problems should also be explored for marital rape and provide counseling and services.

\section{ACKNOWLEDGEMENT}

We would like to acknowledge Public Health Concern Trust (phect-NEPAL), especially to Dr. Bharat Pradhan, Executive Director, phect-NEPAL and Ms. Daniela Colombo, President, Italian Association for Women in Development (AIDOS) for their technical support and full cooperation to conduct this study at health centre in Kirtipur.

\section{DISCLOSURE}

The authors report no conflicts of interest in this work. No violation of human rights and safety.

Funding: Nil

\section{REFERENCES}

1. WHO/RHR/HRP. Perspectives on sexual violence during early years of marriage in

2. Nepal: findings from a qualitative study: social science research policy briefs. Geneva: World Health Organization; 2009. p. 4.

3. Chaudhary P, Chaudhary SK, Shrestha M. Prevalence of gender based violence among pregnant women: a hospital based study. NJOG. 2010;5(2):17-22.

4. Sex without consent within marriage in Nepal. Reproductive Health Research POLICY BRIEF. Kathmandu: CHREHPA; 2008.

5. Sudha S, Morrison S. Marital violence and women's reproductive health care in Uttar Pradesh, India. JWHI. 2011;21(3):214-21.

6. Campbell JC. Health consequences of intimate partner violence. Lancet. 2002;359(9314):1331-6.

7. Champion JD, Piper J, Holden A, Korte J, Shain RN. Abused women and risk for pelvic inflammatory disease. Western Journal of Nursing Research. 2004;26(2):176-91.

8. The World Health Organization Quality of Life (WHOQOL)BREF. Geneva: WHO; 2004.

9. WHO violence against women instrument: a practical guide for researchers and activists. Geneva: WHO; 2003.

10. Reproductive Health Clinical Protocol for Medical Officer Kathmandu: MOHP/FHD ; 2007.
11. WHO Multi-country study on women's health and domestic violence against women. Geneva: WHO; 2005.

12. Nepal Demographic Health Survey (NDHS). Kathmandu: MOHP/FHD; 2011

13. Deuba AR, Rana PS. A study on linkages between domestic violence and pregnancy. Kathmandu: Samanata-Institute for Social and Gender Equality, Population Council; 2005.

14. Puri M, Tamang J, Shah I. Suffering in silence: consequences of sexual violence within marriage among young women in Nepal. BMC Public Health. 2011;11:29.

15. Testa M. The impact of men's alcohol consumption on perpetration of sexual aggression. Clinical Psychology Review. 2002;22(8):1239-63.

16. Lamichhane P, Puri M, Tamang J, Dulal B. Women's status and violence against young married women in rural Nepal. BMC Women's Health. 2011;11:19.

17. Schei B, Bakketeig LS. Gynecological impact of sexual and physical abuse by spouse. A study of a random sample of Norwegian women. BJOG. 1989;96(12):1379-83.

18. Campbell R, Lichty LF, Sturza M, Raja S. Gynecological health impact of sexual assault. Research in Nursing and Health. 2006;29(5):399-413.

19. Boucher S, Lemelin J, McNicoll L. Marital rape and relational trauma. Sexologies. 2009;18(2):95-7. 